\title{
DNA-Sequenzauswahl und ihr Einfluss auf die Hybridisierung auf SPR-Mikroarrays
}

\author{
Alfred Kick ${ }^{1}$ und Michael Mertig ${ }^{1,2}$ \\ ${ }^{1}$ Professur für Physikalische Chemie, Mess- und Sensortechnik, Technische Universität Dresden, \\ 01062 Dresden, ${ }^{2}$ Kurt-Schwabe-Institut für Mess- und Sensortechnik e.V. Meinsberg, Kurt- \\ Schwabe-Straße 4, 04720 Ziegra-Knobelsdorf
}

\section{Zusammenfassung}

In dieser Arbeit wird auf Grundlage experimenteller Ergebnisse an einem computergenerierten Modellsystem gezeigt, wie DNA-Sequenzen die Detektion von Hybridisierungen auf einem DNAMikroarray beeinflussen. Die Ergebnisse zeigen, dass neben Kreuzhybridisierungen auch Sekundärstrukturen (z. B. Haarnadelstrukturen) vermieden werden. Anderenfalls verringert sich die Empfindlichkeit und Nachweisgrenze des Sensors. Die vorgestellten Untersuchungen beruhen auf dem Messprinzip der Oberflächenplasmonenresonanzspektroskopie (SPR). Es ist eine markierungsfreie Methode. Die Sensorschicht besteht aus einem $50 \mathrm{~nm}$ dicken Goldfilm, auf dem einzelsträngige und thiolmodifizierte SondenDNA immobilisiert ist. Die Adresssequenzen dieser Sonden werden als Anti-TAGs bezeichnet. Detektiert wird die Hybridisierung von einem Produkt der Polymerase-Kettenreaktion (PCR). Das PCR-Produkt besteht aus einer 300 Basenpaar-langen Doppelhelix mit einem 25 Basen-langen einzelsträngigen Überhang (TAG), der komplementär zu einer Anti-TAG-Sequenz ist (TAG/Anti-TAG-System).

\section{Motivation}

Eine schnelle, empfindliche und spezifische Detektion von DNA-Hybridisierungen ist von entscheidender Bedeutung für die medizinische bzw. genetische Diagnostik. Insbesondere werden dafür DNA-Chips mit immobilisierten DNA-Sonden eingesetzt. Die Sequenzen dieser Sonden müssen komplementär zu spezifischen DNA-Zielsequenzen sein. Bei der Auswahl dieser Sequenzen müssen verschiedene Aspekte berücksichtig werden, um qualitativ hochwertige Mikroarrays mit zufriedenstellenden, vergleichbaren und dadurch validierbaren Signalen aller Spots zu erhalten. Dazu müssen ähnliche Schmelztemperaturen der Sonden gewährleistet sein. Kreuzhybridisierungen und Sekundärstrukturen (z. B. Haarnadelstrukturen) sollten vermieden werden.

Werden biologisch relevanten Sequenzen für die Sonden gewählt, ist die Auswahl dieser beschränkt. Kann man aber die spezifische Hybridisierung mit entsprechenden genetisch interessanten Bereichen auf die Polymerase-Kettenreaktion (PCR) beschränken und damit von der Detektion auf dem Mikroarray entkoppeln, ist die Entwicklung eines universellen Ansatzes für den Sensor möglich. Dabei ist eine eindeutige Adressierung der PCR-Produkte zu entsprechenden Sonden von entscheidender Bedeutung. [1, 2] Ansätze mit mehreren unterschiedlichen Primerpaaren (Multiplex-PCR) können beispielsweise so analysiert werden. Während die PCR-Produkte einzelsträngige Überhänge mit so genannten TAG-Sequenzen tragen, sind auf der Sensoroberfläche Sonden mit Anti-TAG-Sequenzen immobilisiert. Die Sequenzen des TAG/Anti-TAGSystems sind unter diesen Umständen bei der Berücksichtigung von Kreuzhybridisierungen, Haarnadelstrukturen und des zu untersuchenden genetischen Systems frei wählbar.

In dieser Arbeit wurden bei der computergestützten Generierung der Modell-TAGs die Möglichkeiten zu Kreuzhybridisierungen vermieden, bei denen 7 Basen-lange Teilsequenzen der TAGs untereinander identisch oder komplementär sind. Das heißt, jede 7 Basen-lange Teilsequenz tritt unter allen 7 Basen-langen Teilsequenzen der TAGs nur einmal auf, wobei auch ihre komplementäre Sequenz nicht vorkommt. Die Modell-TAGs wurden mit und ohne Sequenzen generiert, die zur Bildung von Haarnadelstrukturen führen können. 
Haarnadelstrukturen bei DNA-Einzelsträngen bestehen aus einer Stamm- und einer Schleifenstruktur. Die Stammstruktur bildet den doppelsträngigen Bereich mit komplementären Sequenzen während die Schleifenstruktur bei der Faltung einzelsträngig bleibt (Bild 1).

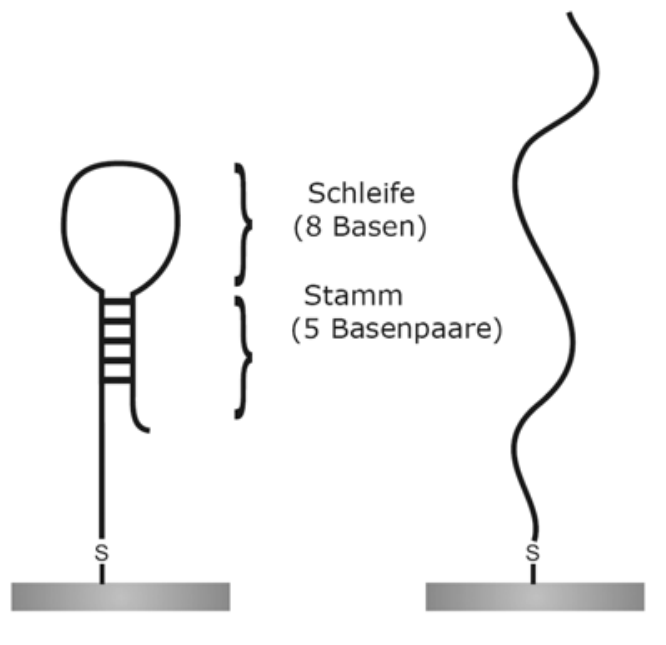

\section{Anti-TAG4}

Anti-TAG17

Bild 1 Anti-TAG-Sekundärstrukturen. Sequenzen in Tafel 1. Links: Schematische Darstellung einer Haarnadelstruktur mit einzelsträngiger Schleife und doppelsträngigem Stamm von Anti-TAG4. Rechts: Keine Faltung bei Anti-TAG17.

Studien über Haarnadelstrukturen zeigen, dass geringere Hybridisierungsgeschwindigkeiten und niedrigere Signale auf Sondenorten mit Haarnadelstrukturen zu erwarten sind. [3, 4] Daher wurden Sequenzen generiert, die teilweise Sekundärstrukturen ausbilden können, um ihren Einfluss auf die Signalstärken bei der Detektion zu untersuchen.

Die Experimente wurden basierend auf Oberflächenplasmonenresonanzspektroskopie (SPR) durchgeführt, was eine markierungsfreie Detektion der Hybridisierung erlaubt. [5] Der Aufbau der Sensorschicht erfolgte durch die Immobilisierung einzelsträngiger und thiolmodifizierter Sonden-DNA mit Anti-TAG-Sequenzen auf einem $50 \mathrm{~nm}$ dicken Goldfilm. Die Ziel-DNA, Produkt einer Polymerase-Kettenreaktion (PCR), besteht aus einer 300 Basenpaar-langen Doppelhelix mit einem 25 Basen-langen, einzelsträngigen Überhang mit einer TAG-Sequenz, die komplementär zum definierten Anti-TAG des Mikroarrays ist.

\section{Material und Methoden}

\section{SPR-Plattform:}

Es wurden spritzgegossene Topas ${ }^{\circledR}$-Chips (76 mm x $26 \mathrm{~mm}$ x $4 \mathrm{~mm}$ ) mit integrierter Optik und einer $50 \mathrm{~nm}$ dicken Goldschicht ( $3 \mathrm{~mm}$ x $12 \mathrm{~mm}$ ) verwendet. Das SPR-Spektrometer (Fraunhofer IOF, Jena) beleuchtet drei unterschiedliche, $1 \mathrm{~mm}$ x $10 \mathrm{~mm}$ große Bereichen der Goldoberfläche. Das reflektierte Licht fällt auf den Chip einer CCD Kamera. In einer Dimension werden die Signale örtlich auf 1280 Pixeln aufgelöst. Mit der zweiten Dimension der CCD Kamera (960 Pixel) wird eine winkelaufgelösten Analyse der an der Goldoberfläche reflektierten Intensität ermöglicht. Die Lage der SPR-Minima wird separat für alle 1280 Winkelspektren aufgezeichnet. Die Verschiebungen der Minima werden als SPR-Signale in der Einheit Pixel angegeben.

Mikrofluidik:

Auf dem Chip wird eine Anschlussplatte aus Aluminium mit Wärmetauscher und einer PDMS-Flusszelle aufgesetzt. Der Mikrokanal der Flusszelle ist $120 \mu \mathrm{m}$ hoch und $3 \mathrm{~mm}$ breit. Die Flüssigkeiten werden mittels einer $500 \mu \mathrm{l}$ Spritzenpumpe durch die Flusszelle gedrückt bzw. gezogen. 
Synthese der PCR-Produkte:

PCR-Produkte wurden durch die Verwendung von geeigneten Primer-Paaren synthetisiert. Als Templat diente der pUC19 Vektor. Die PCR-Produkte unterscheiden sich nur in ihrer einzelsträngigen TAG-Sequenz.

Immobilisierung Thiol-modifizierter Sonden-DNA:

Als Sonden-DNA wurde 3'-modifizierte Thiol-modifizierte, einzelsträngige DNA verwendet (Tafel 1). Mittels des Mikropipettiersystems NanoPlotter 2.1 (GeSiM mbH, Germany) wurden 50 pl-Volumina aufgetragen. Es wurden Spotting-Lösungen mit $10 \mu \mathrm{M}$ HS-ssDNA verwendet. Diese Lösungen wurden linienförmig, parallel im Abstand von $140 \mu \mathrm{m}$ aufgetragen. Innerhalb der Linien wurden die Tropfen im Abstand von $36 \mu \mathrm{m}$ abgesetzt. Danach wurden die Chips 30 min mit $1 \mathrm{mM}$ Mercaptohexanol behandelt. [6]

Hybridisierung:

Es wurden $90 \mu \mathrm{l}$ entsprechender PCR-Produkte ( $5 \mathrm{ng} / \mu \mathrm{l}$, in $120 \mathrm{mM} \mathrm{MgCl}$ ) auf die Sensoroberfläche gebracht und 10 min lang über das DNA-Mikroarray im Mikrokanal vor und zurück gepumpt $\left(6 \mu \mathrm{l} / \mathrm{s}, 40^{\circ} \mathrm{C}\right)$. Nach den Hybridisierungen mit unterschiedlichen PCR-Produkten wurde mit $120 \mathrm{mM} \mathrm{MgCl}$ gespült und mit jeweils $100 \mathrm{mM}$ Dinatriumethylendiamintetraacetat $\left(\mathrm{Na}_{2} \mathrm{H}_{2} \mathrm{EDTA}\right)$ und $\mathrm{NaOH}$ dehybridisiert. $[7,8]$

\section{Ergebnisse und Diskussion}

Es wurden Experimente zur Detektion von Hybridisierungen auf einem SPR-Mikroarray durchgeführt. Verschiedene TAG/Anti-TAG-Paare ergaben unterschiedliche Signalhöhen (Bild 2). Anti-TAG4, -TAG5, TAG12, und -TAG15 enthalten selbstkomplementäre Bereiche, welche Haarnadelstrukturen mit einer Stammlänge von 4 Basenpaaren ausbilden können und so zu auffällig niedrigen Signalen führen. Im Fall von TAG12/Anti-TAG12 ist zusätzlich die Bildung von Dimeren denkbar (Tafel 1). Bei der Bildung von Dimeren hybridisieren zwei DNA-Stränge mit gleicher Gesamtsequenz miteinander, weil selbstkomplementäre Sequenzbereiche auftreten.

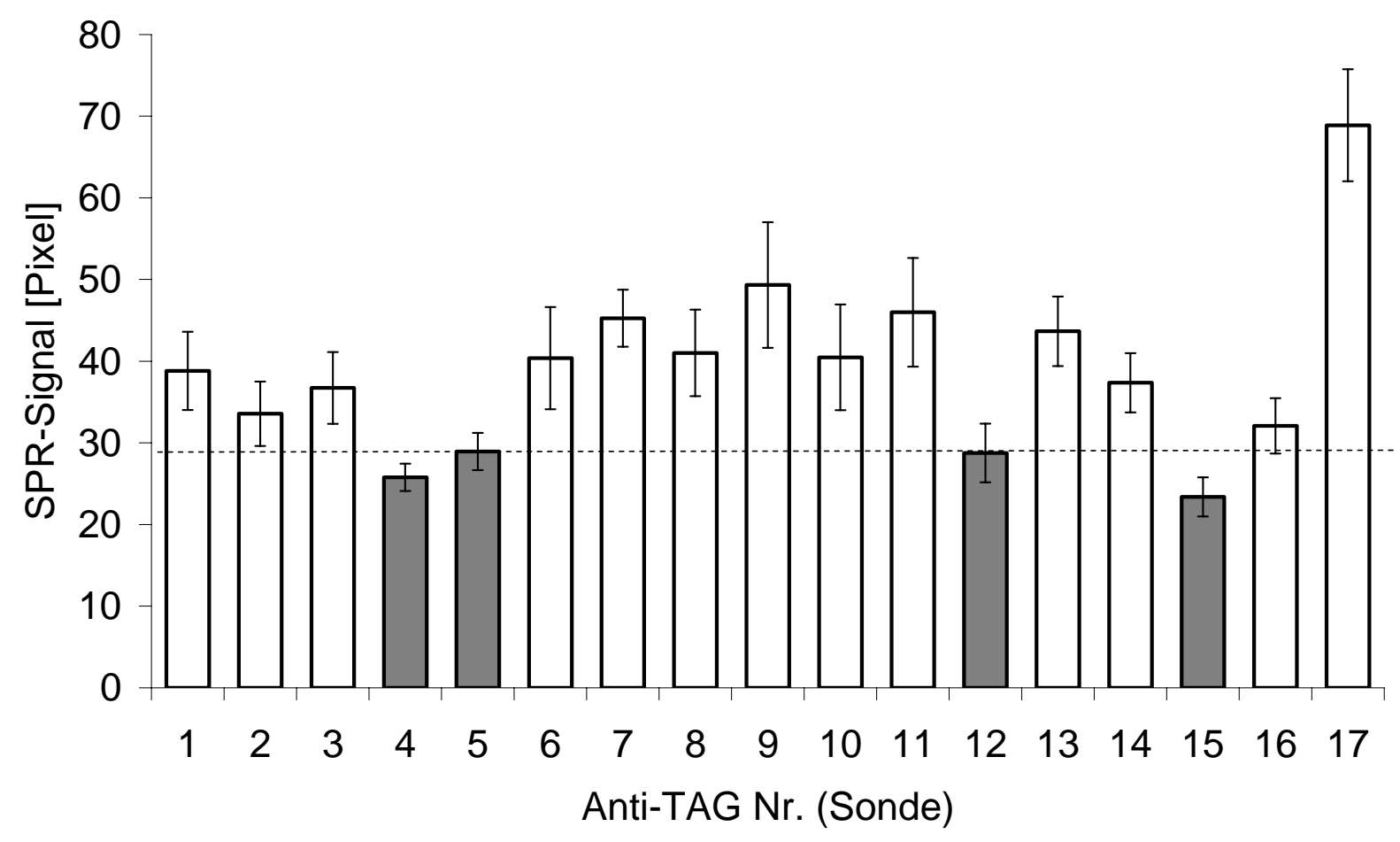

Bild 2 SPR-Signale nach 10 min Hybridisierung mit 5 ng/pl PCR-Produkten auf einem Mikroarray. Mittelwerte und Standardabweichungen der Werte von je 9 Spots eines Chips. Grau hervorgehoben sind auffällig niedrige Signale. Referenziert gegen Spots mit nichtkomplementärer Kontrollsonde. 
Tafel 1 Sonden-Sequenzen. Selbstkomplementäre Bereiche sind fett und unterstrichen.

\begin{tabular}{l|l}
\hline Name & Sequenz $\left(5^{\prime} \text {-3'-(CH}{ }_{2}\right)_{3}$-SH) \\
\hline Referenz ${ }^{1)}$ & ACCGTGAATGGTTGCAGTCCAACCATTTTTTTT \\
\hline Anti-TAG1 & TCCTACCGAAGCAAGTGCACGCAATTTTTTTTT \\
\hline Anti-TAG2 & TCGAATTGGCGGCATCTCATACCGATTTTTTTT \\
\hline Anti-TAG3 & TGTTGTTGCTAACCGACGTCCGTTCTTTTTTTT \\
\hline Anti-TAG4 & GTTACGTCCTCCAACACGTACGCATTTTTTTTT \\
\hline Anti-TAG5 & ACACCGCACATTCAGTCATAGTGCATTTTTTTT \\
\hline Anti-TAG6 & ATTATCCAGATACGGTCGAAGCGGCTTTTTTTT \\
\hline Anti-TAG7 & ACAGTCGACATGGCTCAACCGAATATTTTTTTT \\
\hline Anti-TAG8 & GCCGACTGATGTGTTCGATTGTGTTTTTTTTTT \\
\hline Anti-TAG9 & CCTAGTCTACCGCATTCCTCGTCAATTTTTTTT \\
\hline Anti-TAG10 & CATCGTAAGCTCTGTATTCGCACGGTTTTTTTT \\
\hline Anti-TAG11 & GTCGCAGATCCGATTATAGAACGCGTTTTTTTT \\
\hline Anti-TAG12 & GCTACGGCGTATGTTGAGTACCATTTTTTTTTT \\
\hline Anti-TAG13 & CTTGATCGATGTACGGCTAGACACCTTTTTTTT \\
\hline Anti-TAG14 & CATGCTCGCGTTGTTAACTACTTGGTTTTTTTT \\
\hline Anti-TAG15 & AGGTAGATCCTACTCTCGTGATGCTTTTTTTTT \\
\hline Anti-TAG16 & CCAATTATCGCTAGAGTGTGTTGCCTTTTTTTT \\
\hline Anti-TAG17 & ATAGGCTCTCCAGAATAAGGTCTCGTTTTTTTT \\
\hline${ }^{1}$ Sequenz ist nicht komplementär zu TAG-Sequenzen
\end{tabular}

Es kann geschlussfolgert werden, dass Haarnadelstrukturen und Dimere die Nachweisgrenze verringern und berücksichtigt werden müssen, wenn die Vergleichbarkeit der Signale für eine Quantifizierung der Hybridisierungen auf verschiedenen Spots eines Mikroarrays von Interesse ist. [9] Eine Stammlänge von mehr als 4 Basenpaaren ist zu vermeiden.

Außerdem kann mit der SPR-Plattform untersucht werden, ab welcher Länge komplementärer Bereiche messbare Kreuzhybridisierungen auftreten, was eine experimentelle Grundlage für die Optimierung des TAG/Anti-TAG-Systems darstellt. [8]

\section{Danksagung}

Diese Arbeit wurde durch die Sächsische AufbauBank (FKZ: 14120/2447) unterstützt. Die Entwicklung der SPR-Plattform wurde durch das BMBF (03WKBH2F) gefördert. Die PCR-Produkte wurden durch die Biotype Diagnostic GmbH bereitgestellt.

\section{Literatur}

[1] J. N. Hirschhorn, P. Sklar, K. Lindblad-Toh, Y. M. Lim, M. Ruiz-Gutierrez, S. Bolk, B. Langhorst, S. Schaner, E. Winchester, E. S. Lander, Proc. Natl. Acad. Sci. U. S. A. 97 (2000) 12164-12169.

[2] D. D. Shoemaker, D. A. Lashkari, D. Morris, M. Mittmann, R. W. Davis, Nat. Genet. 14 (1996) 450456.

[3] A. Tsourkas, M. A. Behlke, G. Bao, Nucleic Acids Res. 30 (2002) 4208-4215.

[4] A. Tsourkas, M. A. Behlke, S. D. Rose, G. Bao, Nucleic Acids Res. 31 (2003) 1319-1330.

[5] J. Homola, S. Yee, G. Gauglitz: Sensor. Actuat. B-Chem., 54 (1999) 3-15.

[6] A. Kick, M. Bönsch, K. Kummer, D. V. Vyalikh, S. L. Molodtsov, M. Mertig: J.Electron Spectrosc., 172 (2009) 36-41.

[7] M. Mertig, A. Kick, M Boensch, B. Katzschner, J. Voigt, F. Sonntag, N. Schilling, U. Klotzbach, N. Danz, S. Begemann, A. Herr, M. Jung: IEEE Sensors (2009) 392-395.

[8] A. Kick, M. Bönsch, A. Herr, W. Brabetz, M. Jung, M. Mertig: IEEE Sensors (2010) 1636-1639.

[9] A. Kick, M. Bönsch, B. Katzschner, J. Voigt, A. Herr, W. Brabetz, M. Jung, F. Sonntag, U. Klotzbach, N. Danz, S. Howitz, M. Mertig,: Biosens. Bioelectron. 26 (2010) 1543-1547. 